SPOT TESTS FOR

CONTAMINANTS ON ALUMINUM

by

H. S. Hilborn and R. C. Pugh

Pile Materials Division

November 1954

E. I. du Pont de Nemours \& Co.

Explosives Department - Atomic Energy Division

Technical Division - Savannah River Laboratory 


\section{SPOT TESTS FOR CONTAMINANTS ON ALUMINUM}

\section{by}

H. S. Hilborn, R. C. Pugh

Pile Materials Division

November 1954

E. I. du Pont de Nemours \& Co.

Explosives Department. - Atomic Energy Division Technical Division - Savannah River Laboratory

Printed for

The United States Atomic Energy Commission

Contract At $(07-2)-1$ 
DP -88

Page 2

CHEMISTRY

\section{INTERNAL DISTRIBUTION}

Copy No.

1-5. AEC, SROO

Augusta, Ga.

6. R. M. Evans -

B. H. Mackey

7. W. C. Kay - M. H. Smith

Wilmington AED

J. B. Tinker

8. L. Squires -

$\mathrm{H}$. Worthington

9. J. C. Woodhouse

10. J. A. Burns

Engineering Department

11. J. D Ellett -

K. W. Millett

12. W. P. Overbeck

13. T. C. Evans -

Savannah River Plant

R. D. McCrosky

R. B. Fenninger -

14. R. B. Fenni

15. PRD File

II

If

If

16. M. H. Wahl -

C. W. J. Wende

17. J. W. Croach

18. P. H. Permar

19. H. M. Kelley

20. V. I. MontenyohI

21. M. I. Holzworth

22. H. S. H1lborn

23. R. C. Pugh.

24-38. TIS File

39. TIS File Record Copy

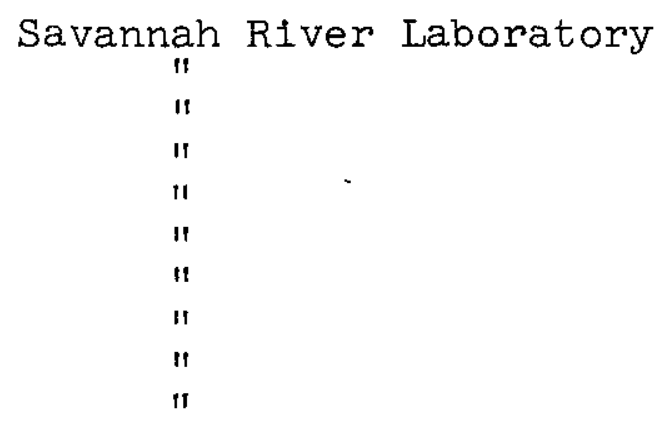


$\mathrm{DP}-88$

Page 3

CHEMISTRY

TID-4500 (8th Ed.)

EXTERNAL DISTRIBUTION

Copy No.

40-45. Argonne National Laboratory

46-50. Armed Services Technical Information Agency, Dayton

51-52. Army Chemical Center

53. Army Medical Research Laboratory

54. Army Medical Service Graduate School

55. Atomic Bomb Casualty Commission (APO-182)

57-56. Atomic Energy Commission, Patent Branch

59. Atomic Energy Commission, Technical Library

60. Atomic Energy of Canada Limited

61. Australian Atomic Energy Commission

62. Battelle Memorial Institute

63. Belgium, Centre d'Etudes pour les Applications de l'Energie Nucleaire

64.66. Belgium, Union Miniere du Haut Katanga

67.70. Brookhaven National Laboratory

71-72. Brush Beryllium Company

73 Bureau of Ships (Code 490)

74. Carbide and Carbon Chemicals Company, C-3I Plant

75-77. Carbide and Carbon Chemicals Company, K-25 Plant

78.83. Carbide and Carbon Chemicals Company, ORNL

84-87. Chalk River Project, Canada

88. Chicago Patent Group

89. Columbia University (Dr. Failla)

90-91. Columbia University (Dr. Hassialis)

92. Consolidated Vultee Aircraft Corporation

93. Department of Army, Office of Ordnance Research

94. Department of Navy, Code 811

$95-96$.

97-98. Dow Chemical Company, Midland

99. Dow Chemical Company, Pittsburg, California

100. Dow Chemical Company, Rocky Flats

101-102. Eldorado Mining and Refining Limited

103. Frankford Arsenal

104. GE Atomic Products Division

105-106. General Electric Company (ANPP)

107-108. General Electric Company, Richland

109-111. Goodyear Atomic Corporation

112. Harshaw Chemical Corporation

113. International Minerals and Chemical Corporation

114-115. Iowa State College

116. Italy, Centro Italian Studi Experienze

117. Johns Hopkins University

118. Kaiser Engineers

119. Kirtland Air Force Base

120-12.2. Knolls Atomic Power Laboratory 


\section{EXTERNAL DISTRIBUTION (Continued)}

Copy No.

123-12/4. Los Alamos Scientific Laboratory

125. Mallinckrodt Chemical Works

126. Massachusetts Institute of Technology (Dr. Hardy)

127. Massachusetts Institute of Technology (Dr. Kaufmann)

128. Merrili Company

129. Mound Laboratory

130. National Advisory Committee for Aeronautics, Cleveland

131-13'c. National Bureau of Standards, Atomic Energy Project

133. National Bureau of Standards, Library

134. National Lead Company, Inc. (Winchester)

135. National Lead Company of ohio

136. National Research Corporation

137-139. National Research Council, Canada

140. Naval Medical Research Institute

141-1:-3. Naval Research Laboratory

144. New Brunswick Laboratory

145. Newport News Shipbuilding and Dry Dock Company

146. New York Operations Office

147. North American Aviation, Inc.

148. Nuclear Development Associates, Inc.

149. Oak Ridge Institute of Nuclear Studies

150-153. Phillips Petroleum Company

154-156. Public Health Service

157. RAND Corporation

158. Sylvania Electric Products, Inc.

159-243. Technical Information Service, Oak Ridge

244. Tokyo University

245. United Aircraft Corporation

246.- 260 . United Kingdom Scientific Mission

261. U. S. Geological Survey (Mr. Butler)

262. U. S. Geological Survey, Denver (Librarian)

263. U. S. Geological Survey, Washington (Iibrarian)

$264-255$. U. S. Naval Radiological Defense Laboratory

266. UCLA Medical Research Laboratory

267-268. University of California Radiation Laboratory

269-271. University of California Radiation Laboratory, Livermore Site

272-273. University of Michigan (Dr. Gomberg)

274-275. University of Rochester, Atomic Energy Project

276. University of Utah

277. Vitro Corporation of America

278. Vitro Manufacturing Company

279. Walter Kidde Nuclear Laboratories, Inc.

280. Watertown Arsenal

281. We11, Dr. George I.

282-28. Westinghouse Electric Corporation 
DP -88

Page 5

\begin{abstract}
The combination of electrolytic sampling with conventional colorimetric spot tests provides a convenient method for identifying small metallic inclusions in aluminum. Tests of particular interest at the Savannah River Plant are compiled for easy reference. Techniques are given for the identification of copper, Iron, lead, magnesium, mercury, molybdenum, $t i n$, and uranium on aluminum. Pinholes may be revealed in aluminum cladding by the detection of nickel or uranium substrates.
\end{abstract}


TABLE OF CONTENTS

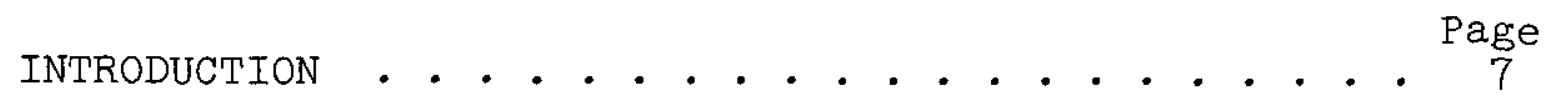

SUMMARY • • • • • • . . • . . • • • . . . . . 7

DISCUSSION • • • • • . . . . . . • . . . . . . . 9

Background . . . . . . . . . . . . . . . . 9 9

Materials and Equipment . . . . . . . . . . . 9

Procedure . . . . . . . . . . . . . . . . 9

Precautions and Suggestions . . . . . . . . . 10

Specific Tests.... . ... . . . . . . . . . 11

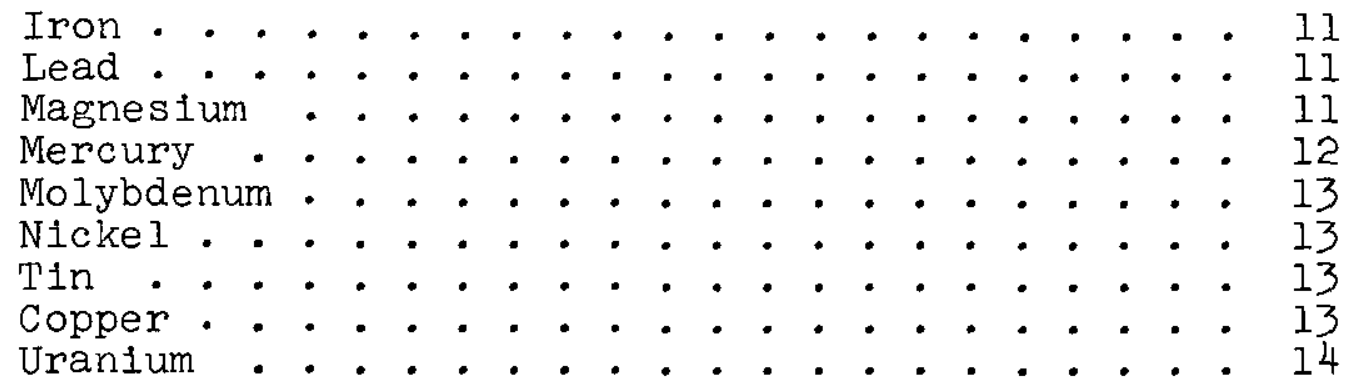

BIBLIOGRAPHY • . . . . . . . . . . . . . . 15

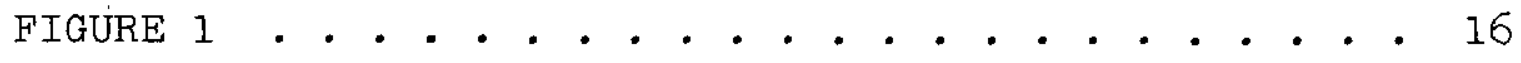

APPENDIX

Preparation and Properties of Reagents . . . . . . 17 
$\mathrm{DP}-88$

Page 7

\section{SPOT TESTS FOR CONTAMINANTS ON ALUMINUM}

\section{INTRODUCTION}

Corrosion of aluminum components that are commonly used in a nuclear reactor may be both dangerous and expensive. Metallic inclusions in aluminum may give rise to galvanic attack with resultant deterioration of the component. The Identification of harmful inclusions is essential if they are to be traced to their source.

The technique employed both by Caley(I) in the analysis of ancient coins and by Alcoal $(2)$ in the identification of certain impurities in aluminum was based on electrographic sampling combined, with colorimetric spot tests of the type described by Feigl(3). Many of the inclusions encountered at Savannah River were not susceptible to investigation by direct application of tests previously described in the literature, so that some adaptation and extension was necessary. This report contains a compilation of tests as finally used to identify inclusions found in aluminum and to ascertain whether the pits in aluminum cladding penetrate to the substrate metal.

\section{SUMMARY}

Procedures were adapted to detect and identify minute quantities of the following metals which may be present as inclusions or alloying constituents:

1. Iron inclusions in aluminum

2. Lead inclusions in aluminum

3. Magnesium on aluminum

4. Mercury on aluminum

5. Molybdenum on aluminum

6. Nickel plating on aluminum

7. Tin on aluminum

8. a. Copper flashing on stainless steel

b. Copper inclusions in aluminum

9. a. Uranium in uranium-aluminum alloy

b. Uranium substrate at corrosion pits or pinholes in aluminum sheath. 


$$
\begin{aligned}
& \text { DP }-88 \\
& \text { Page } 8
\end{aligned}
$$

The methods described are simple, fast, and capable of revealing extremely small quantities of contaminants. The necessary equipment is sufficiently portable to permit its use in the field. 
$\mathrm{DP}-88$

Page 9

DISCUSSION

BACKGROUND

Colorimetric spot tests are well established methods for qualitative analysis. A familiar example is the use of indicator papers for determining relative concentrations of hydrogen or hydroxyl ions in a single drop of solution. Similarly, end points in certain titrations or reactions may be determined by testing single drops of solution with a suitable reagent. Spot tests are now a recognized field in microchemistry in which reactions are studied on a "microdrop" scale. Feigl lists over two-hundred spot tests for over forty metals, including rare-earth elements.

Electrographic sampling is a spot-testing innovation. An early application was the identification of metal constituents in minerals. Jirkovsky (4) has identified iron in pyrite, marcasite, and other iron-bearing minerals. Electrographif sampling has been applied recently by various workers $(1)(2)(4)(5)$ to the identification of both metallic and nonmetallic constituents in alloys.

The procedures described in this report are a combination of the electrographic sampling technique and colorimetric spot tests which were adapted to the study of certain reactor components at the Savannah River Plant.

MATERIALS AND EQUIPMENT

Reagents required for the tests described in this report are, in most instances, those commonly used for colorimetric spot tests previously described by Feigl. Their preparation and properties are given in the Appendix.

The equipment which consists of clips, wire, a sixvolt dry cell, cathodes, and filter paper, is compact and portable. Tests in the field are easy and convenient, facilitating inspection in the field.

PROCEDURE

1. The area of aluminum to be tested is cleaned if necessary using soap and water, alcohol, or acetone.

2. The sample to be tested is made the anode of a galvanic cell by connecting the specimen to the positive terminal of a six-volt dry cell. Depending on the shape and size of the specimen, adequate connection is made by an alligator clip or by resting the specimen on a plate that is connected to the dry cell. 
3. The cathode is prepared by connecting the negative terminal to a stainless steel or aluminum electrode which should be of the proper size and shape to fit the area to be tested.

4. A pad consisting of 2-4 thicknesses of Whatman No. 50 filter paper is prepared.

5. The pad is moistened with the proper electrolyte which should penetrate all the layers of the pad and cover an area at least as large as that to be tested.

6. The molstened pad is then placed on the area to be tested and the cathode is placed on top of 1t. The cathode should be held without movement and it should exert a steady pressure against the pad and specimen. The flow of current through the pad causes metal 1ons to leave the specimen and be deposited in the pad.

7. After 30 to 60 seconds the cathode and pad are removed. The pad now contains a "negative" of the area tested.

8. The "negative" is then developed by spotting the exposed surface of the pad with the proper indicator to form a characteristic colored precipitate or complex with the metal lons removed from the surface of the specimen.

A typlcal setup and test results from it are shown in Flgure 1. PRECAUT IONS AND SUGGESTIONS necessary:

In order for the tests to be satisfactory it is

1. That all electrical contacts be good.

2. That the molstened filter paper pad be in good contact with the test area.

3. That the cathode be in contact with the filter paper pad over the test area.

4. That sufficlent time be allowed for the transfer of lons to take place.

5. In the case of pits, indentations, and pinholes, that the electrolyte fill the cavity before the test is started. 
In some instances, good results are obtained by mixing the electrolyte and indicator before passing current through the cell.

Increased flow of current usually makes the test more positive by causing more metal ions to collect in the f11ter paper pad. The optimum time depends on the individual case and is affected by the size and distribution of inclusions.

The amount of pressure applied to the cathode and the pad also has some effect on the results. A moderately heavy finger pressure is best when using a filter paper pad of the type mentioned previously. The pressure should be constant with no movement of the cathode.

A cross - check on the results, using another test or another indicator if ava1lable, is usually desirable. SPECIFIC TESTS (Reagents described on Page 17)

Iron

Iron inclusions in aluminum Electrolyte: potassium sulfate Indicator: potassium ferrocyanide Alternate indicator: ortolidine solution

This test was successful in identifying iron inclusions in tubing, bar stock, flat stock, and vessels. With potassium ferrocyanide, a light to dark blue spot forms depending on the amount of iron present and time of current flow. If o-tolidine solution is used, copper and iron can be detected simultaneously if they occur as discrete inclusions some distance from each other. Copper will give a blue color as mentioned below, the iron will be distinguished by a reddish brown stain.

Lead

Lead powder lubricant or lead inclusions in aluminum Electrolyte: acetic acid (10\%)

Alternate electrolyte: nitric acid (0.1N) Indicator: potassium lodide

This test was useful in testing for the removal of lead powder that is used as a lubricant on extruded aluminum stock, and in detecting lead inclusions in tubes. A yellow color indicates the presence of lead.

Magnesium

1. Magnesium on aluminum - (test \#I)

Electrolyte: potassium sulfate Indicator: quinalizarin solution 
Two additional steps are required in the procedure. After spotting the filter paper pad with indicator, the pad is held over the mouth of a bottle of concentrated ammonium hydroxide until the indicator turns blue. Then the pad is held over the mouth of a bottle of glacial acetic acid until the indicator turns pink-lavender. A red-violet or red color indicates aluminum, while a blue color indicates magnesium.

2. Magnesium on aluminum - (test \#2)

Electrolyte: potassium sulfate

Indicator: quinalizarin solution

This test follows the general procedure except that after spotting with indicator, sufficient sodium hydroxide is added to dissolve the aluminum hydroxide and to form the aluminate ion. The resulting solution will have a faint-blue tint. However, the insoluble magnesium hydroxide will remain in place and retain the darker-blue color that indicates magnesium.

Both tests were applied successfully in detecting magnesium on tubes and other extruded aluminum stock on which the magnesium was used as a lubricant. They can also detect magnesium in magnesium-aluminum alloys.

Mercury

Mercury on aluminum (a)

Electrolyte: potassium sulfate and nitric acid(b)

Indicator: diphenylcarbazide

Alternate Indicator: p-dimethylaminobenzylidenerhodanine

This test is only moderately successful due to the difflculty encountered in dissolving the mercury(c) without serlously attacking the specimen or cathode.

W1th diphenylcarbazide a deep blue to purple color indicates the presence of mercury, while the p-dimethylaminobenzylidenerhodanine gives a red-violet color.

(a) It is strongly recommended that this test, because of the severe attack on the specimen, be the last test applied.

(b) Try in order - potassium sulfate, IN nitric acid and $8 \mathrm{~N}$ nitric ac1a.

(c) See references 6,7 . 
Molybdenum

\author{
Molybdenum in "Molykote" (molybdenum disulfide) on \\ aluminum \\ Electrolyte: nitric acid (0.1N) \\ Alternate electrolyte: potassium sulfate \\ Indicator: hydrochloric acid \\ potassium thiocyanate \\ sodium thiosulfate \\ Alternate indicator: diphenylcarbazide
}

This test was successful in detecting the

molybdenum in "Molykote" that is used as a lubricant on hotpressed aluminum pieces. The first indicator consists of the reagents added in the order listed. A pink to deep red or blue color is produced depending on the time intervals between the addition of each reagent. The diphenylcarbazide gives a lavender to deep purple color with molybdenum.

\title{
Nickel
}

Nickel plating on aluminum

Electrolyte: potassium sulfate

Alternate electrolyte: acet1c acid (10\%)

Indicator: dimethylglyoxime

This test is satisfactory for determining whether or not a corrosion pit or indentation in an aluminum sheath has penetrated through the entire sheath to nickel plating on the underside. A bright red spot indicates nickel.

Tin

Tin in the presence of aluminum

Electrolyte: acetic acid (5\%)

Indicator: cacotheline

This test was used to detect remnants of tin solders left on aluminum sheeting after corrosion testing. A lavender-to-purple color indicates the presence of tin.

\section{Copper}

1. Copper flash on stainless steel

Electrolyte: potassium sulfate

Indicator: rubeanic acld (dithio-oxamide)

This test proved ideal for identifying very thin copper plating on stainless steel. When the filter paper pad is spotted, an ollve-green to black stain indicates copper. Rubeanic acid must be used since iron, chromium, and nickel interfere with other indicators. 
2. Copper inclusions in aluminum

Electrolyte: potassium sulfate

Indicator: o-tolidine solution

Alternate indicator: rubeanic acid

This test was useful in identifying copper inclusions in tubing, bar stock, and fabricated vessels. With the o-tolidine solution, a light-to-dark blue spot will form depending on the amount of copper present and time of current flow. If rubeanic acid is used, an olive-green to black spot indicates copper.

\section{Uranium}

1. Uranium in uranium-aluminum alloys

Electrolyte: potassium nitrate

Indicator: potassium ferrocyanide

This test is satisfactory for detecting uranium that is present as an alloying element in aluminum. The test is not satisfactory if the alloy has been treated to produce a protective layer of aluminum oxide on the surface. A brown stain or spots indicates uranium.

2. Exposed uranium in corrosion pits and pinholes

in aluminum sheath

Electrolyte: acetic acid (10\%)

Indicator: potassium ferrocyanide

This test was used for determining if uranium has been exposed in corrosion pits and pinholes in aluminum sheaths on clad uranium. A brown stain indicates exposed uranium.

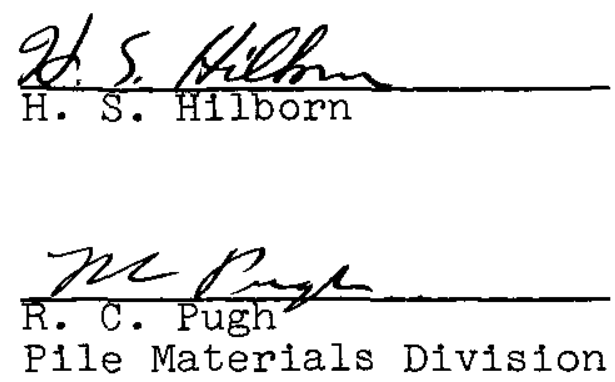




\section{BIBLIOGRAPHY}

1. Caley, E. R. Museum News 15, No. 5, 9-11 (1937). (a)

2. Hunter, M. S., Churchill, J. R., and Mears, R. B. "Electrographic Methods of Surface Analysis." Metal Progress. Vol. 42, 1070-76 (December 1942).

3. Felgl, F. Spot Tests. Vol. l, Fourth Edition, New York: Elsevier Publishing Co. (1954).

4. Jirkovsky, R. Chemical Abstracts. 25, 5640 (1931).

5. ASTM "Symposium on Rapid Methods for the Identification of Metals." (S.T.P. No. 98).

6. Brown, M. H., Binger, W. W., and Brown, R. H. "Mercury and Its Compounds - A Corrosion Hazard." Corr. 8, 155-164 (May 1952).

7. Churchill, J. R. "Mercury and Its Compounds - A Corrosion Hazard." Corr. 8 , 430 (November 1952).

(a) By private communication, Caley states that although he used an electrographic spot-test method, he is not the orlginator of the technique. 


\section{Figure 1}

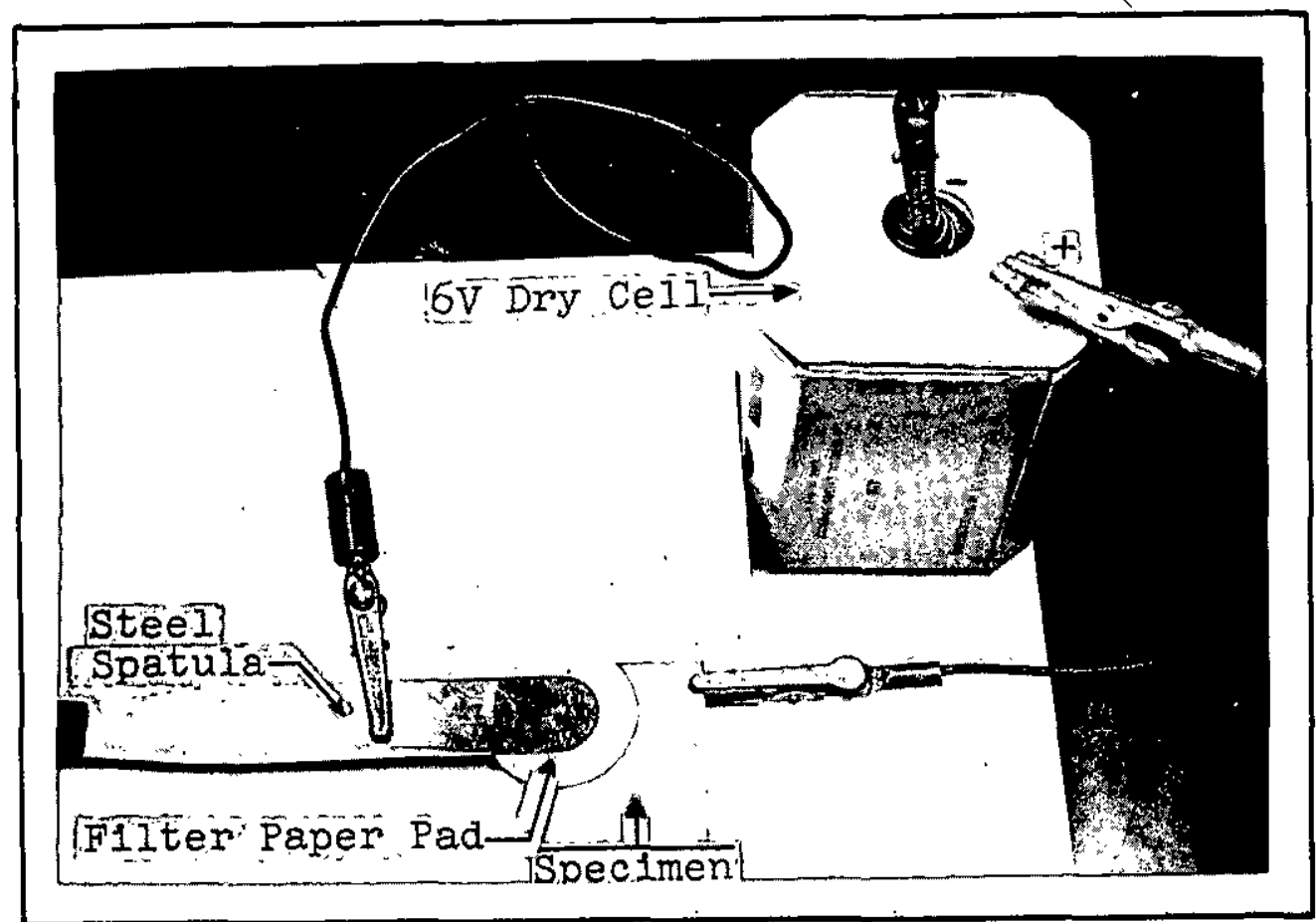

PHOTOGRAPH OF A TYPICAL SPOT TEST SETUP

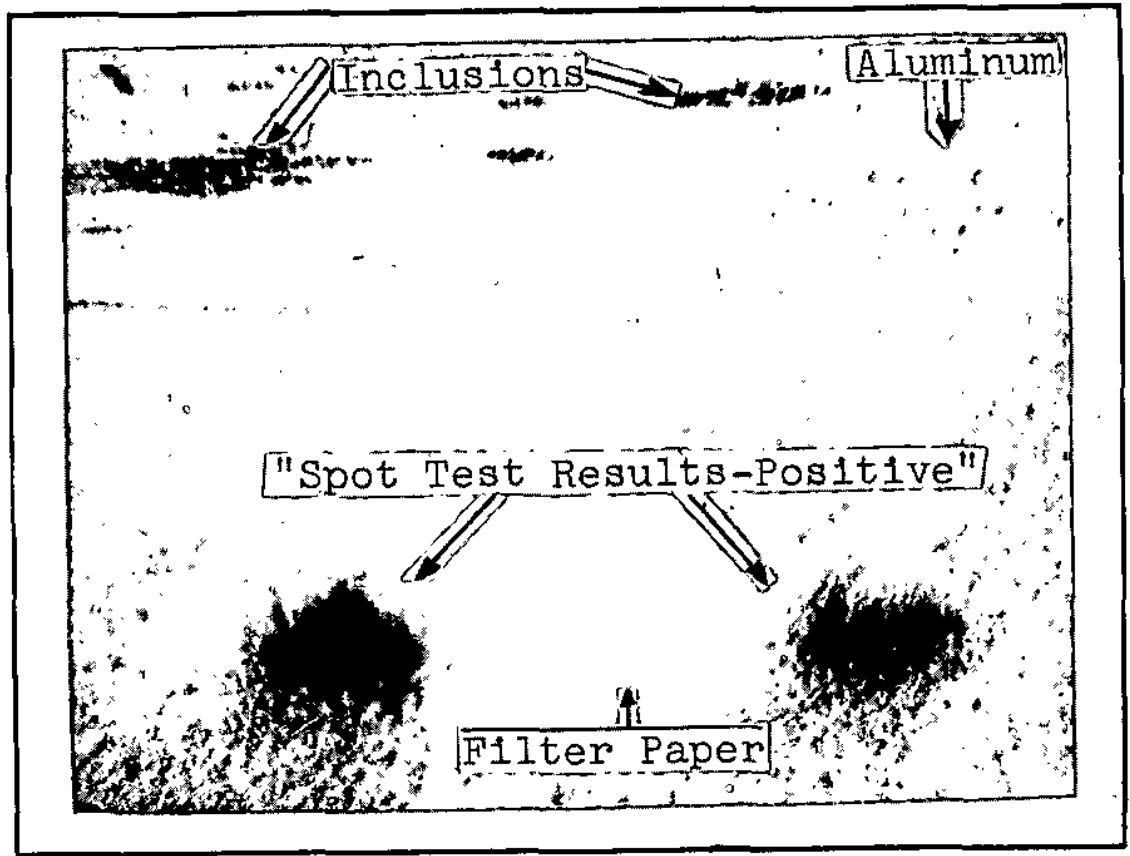

PHOTOGRAPH OF TEST RESULTS Magnification, 10X 


\section{APPENDIX}

\section{PREPARATION AND PROPERTIES OF REAGENTS}

Electrolytes

1. Acetic acid: A 10 per cent by volume solution of acetic acid in water.

2. Acetic acid: A 5 per cent by volume solution of acetic acid in water.

3. Nitric acid: A $0.1 \mathrm{~N}$ nitric acid solution.

4. Nitric acid: A IN nitric acid solution.

5. Nitric acid: A $8 \mathrm{~N}$ nitric acid solution

6. Potassium nitrate: A 10 per cent by weight solution of potassium nitrate in water.

7. Potassium sulfate: A 5 per cent by weight solution of potassium sulfate in water.

\section{Indicators ${ }^{*}$}

1. Cacotheline: A saturated aqueous solution of cacotheline. This indicator reacts with acidic stannous solutions to produce a violet color. Other reducing ions, solutions, or compounds may also react with the indicator and should be absent to insure a specific test. Certain oxides and lons also interfere with the test, for example, colored metallic ions. Arsenic, antimony, molybdenum, and uranium are metals that might be present and which may interfere with the tests.

2. Dimethylglyoxime: A 1 per cent by weight solution of dimethylglyoxime in ethyl alcohol. In neutral or acetic acid solutions this indicator produces a red color with nickel. Large amounts of oxidizing substances may interfere with the test. Of the metals that are most likely to. be present, Iron and copper may interfere.

3. Diphenylcarbazide: A 1 per cent by weight solution of diphenylcarbazide in ethyl alcohol. This indicator gives a violet to blue color with

* For information on the sensitivities of the indicators, and interfering ions, compounds, etc., see references in the bibliography. 
mercury in weakly acid solutions. Chlorides, and iron, copper, and nickel interfere with the test in neutral or weakly acid solutions. In the $8 \mathrm{~N}$ nitric acid, the test is specific but the sensitivity is greatly reduced. This indicator also gives a violet color with molybdenum. This solution should be made up fresh each day.

4. o-Tolidine solution: A solution of $0.1 \mathrm{~g}$ 0 -tolidine and $0.5 \mathrm{~g}$ ammonium thiocyanate in $5 \mathrm{ml}$ of acetone. This indicator gives a blue color with copper and a red-brown color with iron. Mercury and strongly oxidizing metal salts interfere with the test. This solution should be made up fresh each day.

5. p-Dimethylaminobenzylidenerhodanine: A saturated ethyl alcohol solution of p-dimethylaminobenzylidenerhodanine. This indicator gives a red-violet color with mercury. Large amounts of chloride interfere with the test. Copper may interfere with the test in neutral or acetate-buffered solutions.

6. Potassium thiocyanate: A 10 per cent by weight solution of potassium thiocyanate in water. When used with an 8 per cent by volume hydrochloric acid solution and a 25 per cent by welght solution of sodium thiosulfate in water, this indicator gives a pink to deep red color with molybdenum. If the solutions are added slowly with a moderate time lapse between each addition, a blue color may develop, Mercury and other metals or compounds which consume the thiocyanate w1ll interfere with the test. Certain acids also form complexes with the molybdates and thus interfere with the test.

7. Potassium ferrocyanide: A 3 per cent by weight solution of potassium ferrocyanide in water. This indicator gives a blue color' with iron and a red-brown color with uranium. The test of one is interfered with by the presence of the other. Copper and other metals that form colored compounds with the ferrocyanide also interfere. Strong reducing agents will turn the iron compound white.

8. Potassium lodide: A 10 per cent by weight solution of potassium lodide in water. This indicator gives a yellow color with lead. Mercury, copper, and tin may interfere with the test as 


$$
\text { DP - } 88
$$

Page 19

will any material that will produce free lodine. This solution should be colorless.

9. Rubeanic acid (dithio-oxamide): A solution of $0.5 \mathrm{~g}$ rubeanic acid dissolved in $100 \mathrm{ml}$ of ethyl alcohol; of this solution, $5 \mathrm{ml}$ are diluted to $100 \mathrm{ml}$ with water. This indicator gives an olive-green to black spot with copper. Nickel will interfere with this test.

10. Quinalizarin solution: A saturated solution of quinalizarin in ethyl alcohol. This indicator gives a blue color with magnesium. Aluminum may interfere with the test if the alkali concentration is not sufficient. 